\title{
Membrane currents in airway smooth muscle: Mechanisms and therapeutic implications
}

\author{
LUKE J JANSSEN BSc MSc PhD \\ Asthma Research Group, Department of Medicine, McMaster University, Hamilton, Ontario
}

\section{LJ JANSSEN. Membrane currents in airway smooth muscle: Mechanisms and therapeutic implications. Can Respir J 1997;4(1):13-20.}

Electrophysiological and pharmacological techniques were used to characterize the membrane conductance changes underlying spasmogen-evoked depolarization in airway smooth muscle (ASM). Changes included a transient activation of chloride ion channels and prolonged suppression of potassium ion channels; both changes are triggered by release of internally sequestered calcium ion and in turn cause opening of voltage-dependent calcium channels. The resultant influx of calcium ions contributes to contraction as well as to refilling of the internal calcium ion pool. Bronchodilators, on the other hand, act in part through activation of potassium channels, with consequent closure of calcium channels. The tools used to study ion channels in ASM are described, and the investigations of the roles of ion channels in ASM physiology (autacoid-evoked depolarization and hyperpolarization) and pathophysiology (airway hyperresponsiveness) are summarized. Finally, how the relationship between ion channels and ASM function/dysfunction may relate to the treatment of asthma and related breathing disorders is discussed.

Key Words: Airway smooth muscle, Ion channels
Courants membranaires dans le muscle lisse bronchique : Mécanismes et implications thérapeutiques

RÉSUMÉ : On a utilisé des techniques pharmacologiques et électrophysiologiques pour caractériser les changements dans la conductance membranaire sous-jacents à la dépolarisation provoquée par un spasmogène dans le muscle bronchique. On a démontré qu'ils comprenaient une activation transitoire des canaux des ions chlore et une désactivation prolongée des canaux des ions potassium; ces deux types de changements sont provoqués par la libération des ions calcium séquestrés intérieurement et en retour causant l'ouverture des canaux calciques tributaires du potentiel. L'afflux des ions calcium qui en résulte contribue à la contraction ainsi qu'à la recharge du capital calcique interne. Par contre, les bronchodilatateurs agissent en partie par l'activation des canaux potassiques, ce qui entraîne la fermeture des canaux calciques. Les outils ayant servi à l'étude des canaux ioniques dans le muscle lisse bronchique sont décrits, et les investigations relatives aux rôles des canaux ioniques dans la physiologie du muscle lisse bronchique (dépolarisation et hyperpolarisation provoquées par des autocoïdes) ainsi que la physiopathologie (hyperréactivité bronchique) sont résumées. Finalement, la manière dont la relation entre les canaux ioniques et la fonction-dysfonction du muscle lisse bronchique peut se rapporter au traitement de l'asthme et autres troubles respiratoires est discutée.
$I^{n}$ n airway smooth muscle (ASM), the physiologically relevant end-point is contraction, leading to a decrease in airway calibre and thereby an increase in resistance to airflow. Contraction is generally accepted to be calcium-dependent, requiring an elevation of cytosolic levels of calcium ions. One mechanism by which intracellular calcium $\left(\left[\mathrm{Ca}^{2+}\right]_{\mathrm{i}}\right)$ is elevated involves influx of calcium ions through voltage-dependent calcium channels; the membrane depolarization that triggers calcium channel opening is in turn a result of changes in the activity of other ion channels. In

Correspondence and reprints: Dr Luke J Janssen, Department of Medicine, McMaster University, 1200 Main Street West, Hamilton, Ontario L8N 3Z5. Telephone 905-525-9140 ext 22284, fax 905-521-5053, e-mail janssenl@ fhs.csu.mcmaster.ca 
(A)

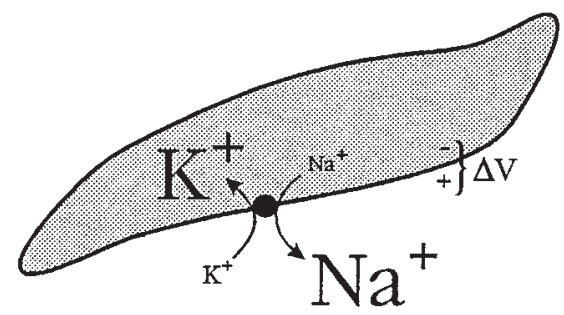

(B)

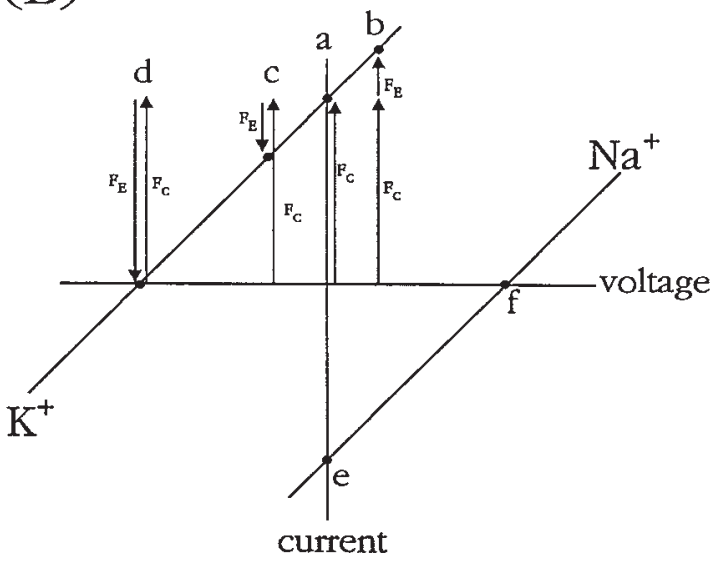

Figure 1) A Smooth muscle cell, showing the concentration gradients for potassium and sodium ions (produced by $\mathrm{Na}^{+} / \mathrm{K}^{+}$-ATPase in the plasmalemma) as well as the voltage gradient $(\Delta V)$ across the membrane. B Current-voltage relationship for potassium ions (line bacd) and for sodium ions (line ef) for the cell depicted in A

addition, elevation of $\left[\mathrm{Ca}^{2+}\right]$ i can be achieved by release of calcium ions from an internal calcium pool; the emptying and refilling of this pool involves ion channels in the membranes of the internal calcium pool as well as the plasmalemma. Finally, asthma and airway hyperreactivity may involve pathophysiological changes in ion channel activity and calcium handling. Thus, ion channels play key roles in the physiology and pathophysiology of ASM. This review focuses on ion channels in ASM and their relevance to the clinical treatment of airway disease.

\section{MEMBRANE CURRENTS}

The movement of electrical charges is referred to as an electrical current (' $I$ '); in the case of ions moving across the cell membrane, this is more specifically referred to as an ionic current or a membrane current. In general, ions move across the membrane through pores that exhibit varying degrees of selectivity for one type of ion or another. The opening and closing of these pores, or ion channels, are often regulated in part by the voltage gradient across the membrane (membrane potential, or ' $\mathrm{V}$ ') ; in addition, the voltage gradient directly influences the movement of the ions themselves (in this light, it is important to point out that movement of one ion species changes $\mathrm{V}$ and thereby influences the movement of other ions). Thus, one common approach taken to studying ion currents is to examine how they are influenced by $\mathrm{V}$ : in other words, the current-voltage (I-V) relationship is obtained. Figure 1A depicts a typical cell, the concentration gradient for potassium that exists across its membrane (approximately 20 to 30 times higher inside than outside the cell) and V. Potassium ions tend to move out of the cell due to the potassium concentration gradient (the chemical driving force, or $\mathrm{F}_{\mathrm{C}}$ ). This large outward current is represented by point a in Figure 1B. If the membrane is made slightly positive inside, there is an electrical driving force $\left(\mathrm{F}_{\mathrm{E}}\right)$, which tends to repulse the potassium ions from the cell and thereby increase the magnitude of the outward current (point $b$ in Figure 1B). Conversely, if the membrane is made slightly negative inside, $\mathrm{F}_{\mathrm{E}}$ opposes $\mathrm{FC}_{\mathrm{C}}$ and the net efflux of potassium ions is reduced (point $\mathrm{c}$ in Figure $1 \mathrm{~B}$ ). As $\mathrm{V}$ is made progressively more negative, the opposing influence of the electrical field increases. At some negative voltage, the electrical field is strong enough to oppose completely the efflux of potassium down its concentration gradient, and the net potassium current is zero (point $d$ in Figure 1B). As V is made yet more negative, $\mathrm{FE}_{\mathrm{E}}$ exceeds $\mathrm{FC}_{\mathrm{C}}$, and there is a net inward potassium current, with $\mathrm{K}^{+}$being accumulated against its concentration gradient.

Line bacd illustrates the potassium I-V relationship for the cell depicted in Figure 1A. To simplify the description of an I-V relationship, electrophysiologists usually refer merely to the point at which the net current is zero, also known as the reversal potential $\left(\mathrm{V}_{\text {rev }}\right)$ since the current reverses direction from being outward to being inward at this voltage. In the hypothetical case of a pore that is permeable only to potassium ions, this $\mathrm{V}_{\text {rev }}$ is also known as the Nernst potential or equilibrium potential for potassium ( $\mathrm{E}_{\mathrm{K}}$, equivalent to point $\mathrm{d}$ in Figure 1B).

An alteration in the gradient necessarily changes the I-V relationship. For example, sodium ions have the opposite concentration gradient, being much higher in concentration outside the cell than inside (Figure 1A). In the absence of an electrical field, sodium ions tend to rush in, giving a large inward current (point e in Figure 1B). As the membrane is made positive inside, the electrical field opposes this inward movement, and the current decreases in size. Eventually, a potential is reached at which the inward $\mathrm{FC}_{\mathrm{C}}$ is exactly balanced by the outward $\mathrm{FE}$, and the net sodium ion current is zero (point $\mathrm{f}$ in Figure 1B). If the membrane is made yet more positive, $\mathrm{F}_{\mathrm{E}}$ exceeds $\mathrm{FC}_{\mathrm{C}}$ and sodium ions are actually driven out of the cell against the concentration gradient.

Thus, the I-V relationships for potassium and sodium ions differ markedly, with $\mathrm{V}_{\text {rev }}$ or equilibrium potentials of points $\mathrm{d}$ and $\mathrm{f}$, respectively, solely due to the different concentration gradients for these two monovalent cations. If the charge on the ions were altered - for example, if they were monovalent anions (eg, chloride ions) or divalent cations (eg, calcium or magnesium ions) - this too would lead to a change in the I-V relationship, since the ions would be influenced in different ways by the electrical field. The charge on an ion and its concentration gradient across the membrane are generally unique to each of the physiologically relevant ions, and 


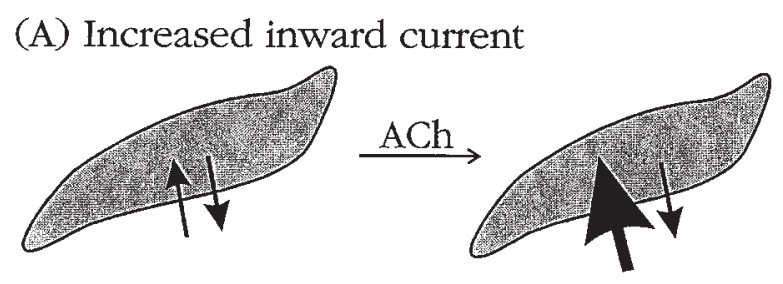

(B) Decreased outward current

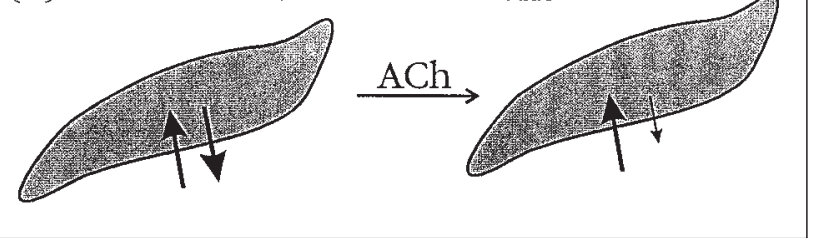

Figure 2) Relationship between membrane depolarization and changes in membrane ion currents. At rest, inward current balances outward current. In the presence of a spasmogen such as acetylcholine (ACh), depolarization results when inward current is increased (A) or when outward current is decreased (B)

thus each ion has a characteristic I-V relationship $\left(\mathrm{V}_{\text {rev }}\right.$; see Figure 4). As a result, an indication of the type of ion or ion channel involved in mediating any given membrane current response can be obtained simply by obtaining the I-V relationship. Furthermore, changing the concentration gradients for different ions - by replacing them with impermeant ion analogues - leads to predictable changes in the I-V relationship of the current responses, as reflected in a shift in Vrev of the current.

Finally, ion channels are large polypeptide molecules with unique amino acid sequences, and a number of pharmacological agents have been identified that interact with one or another type of ion channel; the selectivity of this interaction varies from one agent to another. A comprehensive listing of the different types of ion channels and the pharmacological agents used to study them is beyond the scope of this review.

Thus, several tools are available to characterize ion currents, including voltage clamp electrophysiology (to obtain the I-V relationship), ion substitution experiments, and pharmacological agonists and antagonists. We have used these techniques to characterize the membrane conductance changes underlying depolarization in ASM, as outlined below.

\section{RESTING V AND DEPOLARIZATION}

ASM cells possess a $\mathrm{Na}^{+} / \mathrm{K}^{+}$-ATPase in their plasma membrane that extrudes three sodium ions from the cell and transports two potassium ions into the cell using the energy liberated by the hydrolysis of one molecule of ATP, thereby generating concentration gradients for both sodium and potassium ions (Figure 1A). The net accumulation of negative charge inside compared with the outside of the cell also produces an electrical gradient, or V. However, potassium channels in the membrane allow potassium ions to leave the

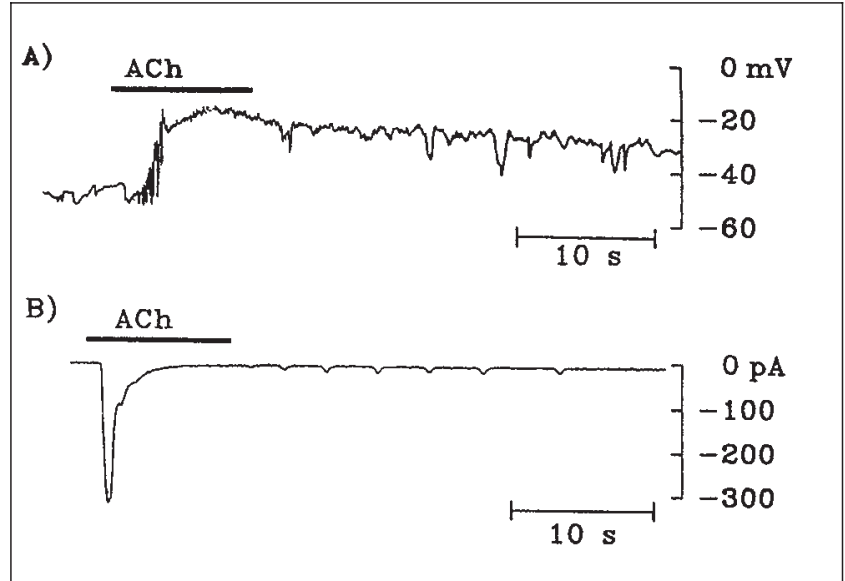

Figure 3) A In a single canine tracheal smooth muscle cell studied using patch-clamp electrophysiological methods, acetylcholine (ACh) caused the membrane to be depolarized from a resting value of approximately $-60 \mathrm{mV}$ to a peak value of approximately $-20 \mathrm{mV}$; repolarization occurred over the next 1 to 2 mins. B In a cell studied under voltage clamp conditions (holding potential of $-60 \mathrm{mV}$ ), ACh evoked a transient inward current that resolved within $5 s$ and was followed by a number of smaller secondary inward currents

cell, resulting in further accumulation of negative charge on the inner face of the membrane and of positive charge outside the membrane. In other words, the membrane becomes highly polarized (generally -60 to $-70 \mathrm{mV}$ on the inside compared with the outside) due to the combined contributions of the sodium-potassium pump and potassium channels.

At rest, inward current across the membrane is balanced by outward current of the same magnitude (Figure 2). Depolarization results when the net inward current is increased (Figure 2A) or the net outward current decreased (Figure 2B). For example, increased inward current results when sodium or calcium channels open and allow these cations to rush into the cell, leading to increased positive charge on the inner face of the membrane and, thus, depolarization (Figure 2A). On the other hand, the same result would be achieved if chloride channels were to open and allow an efflux of chloride ions. Finally, the membrane is hyperpolarized due to the tonic efflux of potassium ions - if this current were suppressed, the hyperpolarizing influence of this ion would be lessened and, again, the membrane would be depolarized (Figure 2B). Thus, the mechanisms that lead to membrane depolarization include increased inward current (due to influx of cations or efflux of anions) and decreased outward current.

\section{MECHANISMS UNDERLYING DEPOLARIZATION OF ASM}

The ionic conductance changes evoked by acetylcholine, histamine and substance $\mathrm{P}$ were examined in single smooth muscle cells from human, canine and guinea-pig airways (1-4). In addition to their effects on mechanical activity, these spasmogens evoke membrane depolarization: from a resting value of approximately $-60 \mathrm{mV}$, the membrane depolarized to approximately $-35 \mathrm{mV}$ within 10 to $20 \mathrm{~s}$, then recovered (ie, repolarized) over the course of 1 to 2 mins (Figure 3A). 


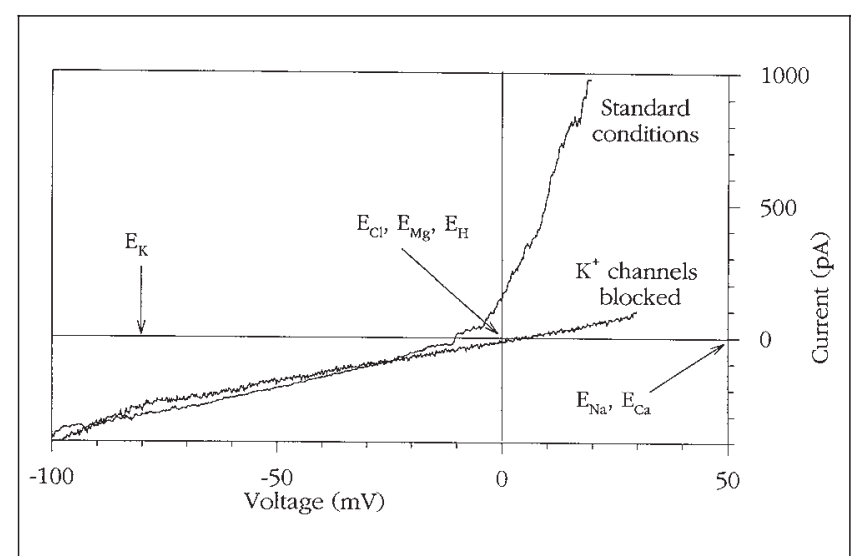

Figure 4) The current-voltage relationship for the acetylcholineevoked membrane conductance change in human bronchial smooth muscle. When a standard (ie, potassium-containing) electrode solution was used, this relationship was inward and linear at negative potentials, reversed direction at -10 to $-15 \mathrm{mV}$, and became outward at more positive potentials. When potassium conductances were blocked (by replacing internal potassium ions with cesium ions), the relationship was linear over the whole voltage range tested, and the reversal potential was displaced towards $0 \mathrm{mV}$. The approximate values of the equilibrium potentials (E) for various ions (chloride, magnesium, hydrogen, sodium, calcium and potassium) are also indicated

To characterize the membrane currents responsible for this depolarization, the cells were studied under voltage clamp conditions. When the membrane is clamped at the resting potential of $-60 \mathrm{mV}$, spasmogens evoke a large and transient inward current that reaches a peak value within $5 \mathrm{~s}$, then reverses to basal levels within $10 \mathrm{~s}$ after application of the spasmogen (Figure 3B). In some cells, this large inward current is followed by a series of smaller secondary inward currents. Since this inward current is in part responsible for the membrane depolarization, we sought to characterize the type of ion channels involved using the approaches summarized in the Membrane Currents section above.

First, the I-V relationship of the inward current was examined. Under physiological conditions, this relationship is linear and inward at negative $\mathrm{V}$, reverses direction at -10 to -15 $\mathrm{mV}$, then curves exponentially upward as the membrane is made more positive than $V_{\text {rev }}$ (Figure 4). This $V_{\text {rev }}$ does not correspond to the Nernst potential for any single ion species (indicated in Figure 4), suggesting that the spasmogens evoke a mixed conductance change, that is, that more than one type of ion channel is involved in the excitatory response.

Potassium is the only ion with a Nernst potential negative to the observed $\mathrm{V}_{\text {rev }}$, while all the other Nernst potentials are positive to it (Figure 4), suggesting that potassium channels must be opened during application of acetylcholine. This prediction was confirmed by blocking potassium channels in a nonselective fashion by replacing internal potassium ions with the nonpermeant cesium cation (Figure 4); the result is a shift in the $\mathrm{V}_{\text {rev }}$ of the agonist-evoked current away from $\mathrm{EK}_{\mathrm{K}}$ and towards $0 \mathrm{mV}$, as well as elimination of the large, exponentially increasing outward current at potentials positive to $-25 \mathrm{mV}$ (ie, the $\mathrm{I}-\mathrm{V}$ relationship becomes linear over

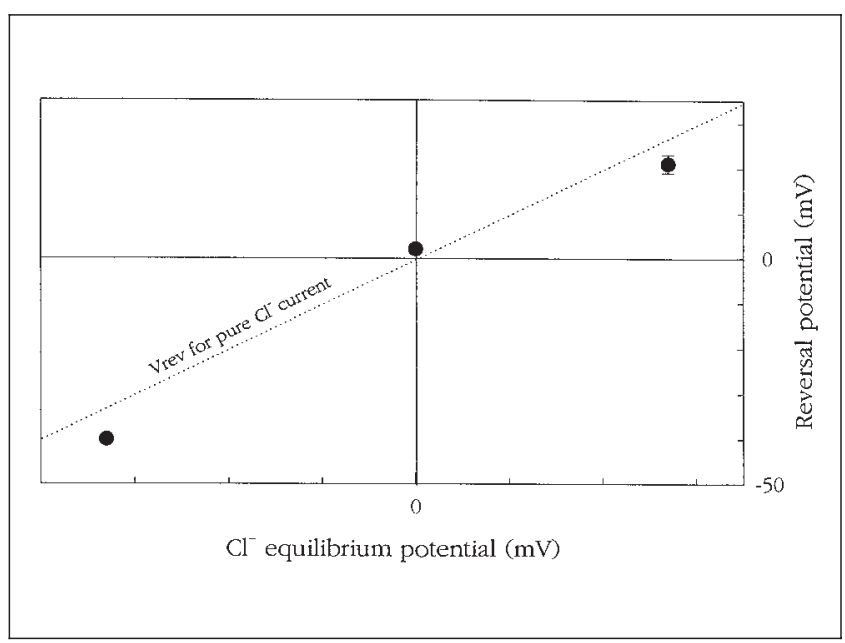

Figure 5) The reversal potential $\left(V_{\text {rev }}\right)$ for the acetylcholine-evoked conductance change in human bronchial smooth muscle was obtained under conditions in which potassium channels were blocked (by cesium) and the internal or external concentration of chloride ions was varied (by being replaced with the impermeant anion aspartate, resulting in a change in the chloride equilibrium potential). There was a close correspondence between the observed $V_{\text {rev }}$ and that expected of a pure chloride current (ie, $E_{C l}$, indicated by the dotted line)

the entire range of potentials tested). Both observations indicate that the spasmogens are able to activate potassium channels under experimental conditions. However, this finding is surprising, since activation of potassium channels is by nature an inhibitory event, leading to hyperpolarization, not depolarization. It should be pointed out that, over the range of potentials found in nature - beginning with resting potential $(-70$ to $-60 \mathrm{mV})$ and extending to those observed during maximal excitation $(-20$ to $-10 \mathrm{mV})$ - the effect of blocking potassium channels is negligible. Thus, opening of potassium channels may occur under nonphysiological conditions but contributes little to the spasmogenic response in vivo.

The inward current remaining following blockade of potassium channels, however, is directly responsible for depolarization. This current is linear over the entire range of potentials and reverses direction at approximately $0 \mathrm{mV}$ (Figure 4), which corresponds to $\mathrm{E}_{\mathrm{Cl}}, \mathrm{E}_{\mathrm{Mg}}$ or $\mathrm{E}_{\mathrm{H}}$. This $\mathrm{V}_{\text {rev }}$ also corresponds to a $\mathrm{V}_{\text {rev }}$ typical for a class of ion channels referred to as nonselective cation channels, which discriminate poorly among the various cations. These different possibilities were explored by altering the intracellular and extracellular concentrations of the various ions, which alter their concentration gradients and therefore result in predictable changes in the observed $\mathrm{V}_{\text {rev }}$. It was found that manipulating cationic concentrations leads to relatively small and sometimes unpredictable changes in the agonist-evoked response. In contrast, when $\mathrm{E}_{\mathrm{Cl}}$ was displaced in the positive direction (by replacing external chloride ions with the impermeant anion aspartate), $\mathrm{V}_{\text {rev }}$ was displaced approximately $25 \mathrm{mV}$ in the positive direction, while replacing internal chloride ions (to displace $\mathrm{E}_{\mathrm{Cl}}$ in the negative direction) shifted the reversal approximately $25 \mathrm{mV}$ in the negative 


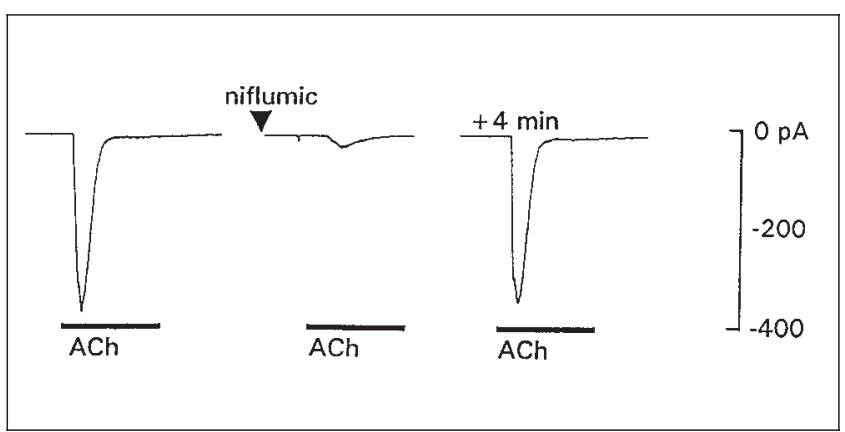

Figure 6) In a smooth muscle cell held under voltage clamp at -60 $m V$, acetylcholine (ACh) evoked a transient inward current. Pretreatment of the cell with the chloride channel blocker niflumic acid markedly reduced the response to ACh; washout of the channel blocker was accompanied by rapid recovery of the cholinergic response

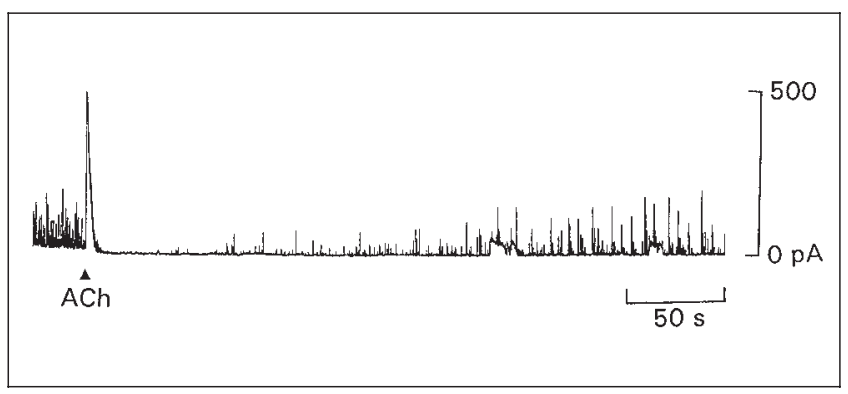

Figure 7) In a human bronchial smooth muscle cell held under voltage clamp at $0 \mathrm{mV}$, the membrane current trace was characterized by a series of spontaneous transient outward currents, manifested as spike-like upward deflections. These spontaneous currents are widely accepted to reflect activation of potassium channels. Acetylcholine (ACh) evoked a large and transient current that is outward at this holding potential but inward at $-60 \mathrm{mV}$ (see Figure $3 B$ ) and that represents activation of chloride channels. This transient current was followed by a prolonged suppression of the spontaneous potassium ion currents present before application of $\mathrm{ACh}$; recovery of spontaneous potassium ion currents occurred over the course of several minutes

direction; Figure 5 shows the close correspondence between the observed $\mathrm{V}_{\text {rev }}$ and that expected for a pure chloride ion current. These findings suggest that chloride channels are involved. Furthermore, chloride channel blockers markedly and reversibly attenuated the membrane current response to the spasmogens (Figure 6). Thus, the depolarization evoked by the spasmogens involves a transient activation of chloride channels; these were later shown to be of a very small conductance, calcium-dependent variety of chloride channel $(5,6)$.

However, the chloride channel response cannot alone account for the depolarizing response, since the former is much more transient (lasting less than $10 \mathrm{~s}$ ) than the latter (which persists up to $1 \mathrm{~min}$ ) (Figure 3). Clearly, some other conductance change contributes to the depolarization. The nature of this conductance change was revealed during a study of spontaneous potassium currents in these cells $(1,3,4)$. In cells held under voltage clamp at relatively depolarized potentials, a series of large spike-like outward currents is observed.

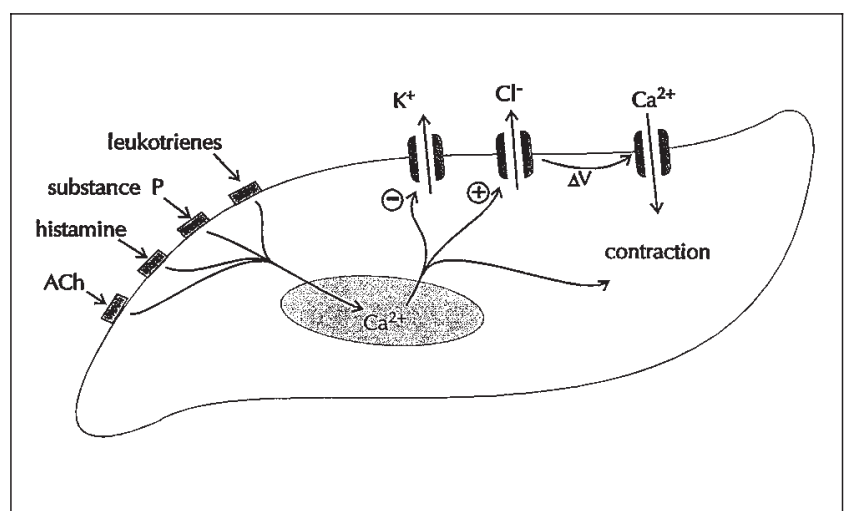

Figure 8) Convergent signalling pathway by which spasmogens mediate their effects on airway smooth muscle. Following activation of their respective receptors, these spasmogens release a common pool of calcium ions, which in turn triggers, first, contraction; second, transient activation of chloride channels; and third, prolonged suppression of potassium channels. The changes in chloride and potassium channel activity are responsible for membrane depolarization, which leads to opening of voltage-dependent calcium channels. The resultant calcium ion influx contributes further to contraction as well as refilling of the internal calcium ion pool. ACh Acetylcholine; $\Delta V$ Voltage gradient

These spontaneous transient outward currents (STOCs) are generally accepted to reflect the opening of calcium-dependent potassium channels in response to a transient elevation of calcium ion concentration at the inner face of the membrane following a brief 'trickle' of calcium ions from the internal calcium pool. As such, STOCs can be used as an index of potassium channel activity in these cells. It was found that, following the initial transient chloride current response (which is outward at $0 \mathrm{mV}$ [Figure 7] but inward at $-60 \mathrm{mV}$ [Figure 3]), there is a complete suppression of STOC activity (Figure 7). This suppression is relatively prolonged, reversing over the course of several minutes, as is the case for membrane depolarization (Figures 3,7). Since potassium channels are largely responsible for hyperpolarizing the membrane at rest (see the Resting V and Depolarization section above), the spasmogen-induced suppression of potassium channel activity lessens this hyperpolarizing influence and thereby mediates a prolonged depolarization.

Thus, spasmogen-induced depolarization of ASM is a product of a transient opening of chloride channels (increased inward current) followed by a prolonged suppression of potassium channels (decreased outward current) (Figure 8).

\section{MECHANISMS UNDERLYING HYPERPOLARIZATION OF ASM}

In addition to their relaxant effects, beta-adrenoceptor agonists, the neuropeptide vasoactive intestinal peptide and nitric oxide cause hyperpolarization. Electrophysiological studies indicate that this change in $\mathrm{V}$ involves an increase in membrane permeability (ie, opening of channels). Since the only ion with an equilibrium potential negative to resting $\mathrm{V}$ is potassium, it seems likely that potassium channels are directly involved. Consistent with this suggestion, the hyperpolarizing and relaxing effects of beta-agonists are antago- 
nized by nonselective potassium channel blockers such as tetraethylammonium or procaine (7-11). The type of potassium channels appears to be of a large conductance calciumdependent variety, since the effects of the bronchodilators are also sensitive to agents such as charybdotoxin and iberiotoxin (12) (which are relatively selective blockers of this type of potassium channels). More recently, patch-clamp techniques have been used to record directly the opening of calcium-dependent potassium channels by isoprenaline (13). The coupling between beta-adrenoceptors and potassium channels seems to involve phosphorylation of the channels by cAMP-dependent protein kinase $(7,12-16)$. By opening calcium-dependent potassium channels, bronchodilators hyperpolarize the membrane to potentials that lead to closure of voltage-dependent calcium channels, thereby abrogating contractile activity.

\section{ION CHANNELS AND THE CLINICAL TREATMENT OF AIRWAY DISEASE}

Potential roles for ion channels in ASM pathophysiology:

Asthma is characterized by bronchoconstriction and airway hyperresponsiveness to a variety of constrictor agents including cholinergic agonists, histamine and the leukotrienes (17). It is now recognized that airway inflammation - triggered by stimuli such as allergens, viral infections, chemical sensitizing agents (eg, ozone) and exercise - plays an important causal role in the mechanism(s) underlying asthma and airway hyperresponsiveness (17). The general consensus is that these stimuli activate mast cells, lymphocytes, macrophages and epithelial cells in the airways, causing them to release a host of proinflammatory mediators and cytokines. The latter, in turn, promote activation, chemotaxis and degranulation of eosinophils, neutrophils and lymphocytes. The ultimate response to this outpouring of mediators and cytokines includes effects on the smooth muscle (contraction, airway hyperresponsiveness), epithelium (secretion, denudation), innervation (release of tachykinins) and vasculature (edema) (17).

The nonspecific nature of airway hyperresponsiveness suggests that a postreceptor mechanism may in part be responsible, such as changes in $\left[\mathrm{Ca}^{2+}\right]_{i}$, excitation-contraction coupling or calcium ion sensitivity of the contractile apparatus (18-20). Several models of airway hyperresponsiveness have been developed, all of which involve induction of an inflammatory response in the airway tissues (eg, by exposure to allergens or proinflammatory mediators and cytokines). Recent studies using such preparations have indicated possible roles of ion channels in the mechanisms underlying the pathology. For example, in canine and guinea-pig tracheal smooth muscle, ovalbumin, immunoglobulin $\mathrm{G}_{1}$ and the proinflammatory cytokine interleukin (IL) $-1 \beta$ evoke membrane depolarization, which is blocked by preventing sodium influx (by removing external sodium or using amiloride) $(21,22)$. Depolarization is followed by a marked and prolonged hyperpolarization that is sensitive to ouabain (which inhibits $\mathrm{Na}^{+} / \mathrm{K}^{+}$-ATPase) $(21,22)$. Both changes in $\mathrm{V}$ are blocked by certain protein kinase inhibitors (21). The mecha- nism that has been proposed to account for these observations involves increased membrane permeability to sodium $(21,22)$. The resultant influx of sodium ions produces three effects, the first of which is a transient membrane depolarization. Second, accumulation of sodium ions in the cytosol suppresses sodium-calcium exchange activity, leading to accumulation of calcium ions and, thus, augmentation of the contractile responses to spasmogens (ie, hyperreactivity). Third, accumulation of sodium ions stimulates $\mathrm{Na}^{+} / \mathrm{K}^{+}$-ATPase, with consequent and sustained membrane hyperpolarization.

Calcium channel activity may also be altered in airway hyperreactivity. For example, passive sensitization of human bronchial smooth muscle increases the involvement of voltage-dependent calcium channels in the contractile response to potassium chloride (23). In contrast, IL-1 $\beta$ suppresses voltage-dependent calcium current in rat ventricular muscle cells (24).

Thus, ion channels may play key roles in the mechanisms underlying airway hyperresponsiveness.

$\mathbf{K}^{+}$channel openers: Inhaled beta-agonists may act in part by mediating membrane hyperpolarization with subsequent closure of calcium channels. Unfortunately, continuous stimulation by beta-agonists leads to down-regulation of the beta-adrenoceptors and, thus, decreased sensitivity to endogenous or inhaled beta-agonists. In light of this, it may be useful to activate potassium channels directly, without the need to act through the adrenoceptors. A number of agents have recently been developed that do just this, including a racemic mixture referred to as cromakalim (BRL 34915) and the active enantiomer levcromakalim (BRL 38277) $(12,25,26)$. These agents directly hyperpolarize ASM by opening a subpopulation of receptors that are distinct from the channels to which the beta-receptors are coupled, since they are insensitive to charybdotoxin (which blocks calciumdependent potassium channels) but are antagonized by glibenclamide (which blocks ATP-dependent potassium channels), while the opposite is true of the responses to beta-agonists $(9,10,12,16)$. However, there have been no direct electrophysiological studies to distinguish clearly the involvement of these two types of potassium channels. The use of these potassium channel agonists in the management of airway diseases merits further investigation.

Commonly used antiallergic and antibiotic substances: Since it is believed that the sequence of events leading to asthma begins with airway inflammation, the widely accepted prophylactic approach to the treatment of asthma is the use of anti-inflammatory agents, of which the most effective are inhaled corticosteroids $(17,27)$. In addition to steroids, other drugs including cromolyn sodium, nedocromil, the diuretic furosemide and theophylline mediate a variety of effects including suppression of the release of inflammatory mediators and cytokines from mast cells (17,27-29). However, there is still considerable controversy with respect to the precise mechanism of action of these nonsteroidal antiinflammatory agents $(17,27-29)$.

Recently, a number of the nonsteroidal anti-inflammatory 
agents have been found to exert previously unsuspected effects on ion channels. For example, cromolyn sodium and RU 31156 (a synthetic antiallergic) block chloride channels (intermediate conductance type) in cultured mast cells and colonic carcinoma cells (30). Nedocromil blocks a chloride current (outwardly rectifying, calcium-insensitive) in mouse 3 T3 fibroblasts (31). In rabbit vagal C-fibres, however, nedocromil first activates chloride channels, then suppresses them (32). The diuretic furosemide activates potassium currents in the apical membrane of amphibian diluting segment (33) and suppresses allergen-induced contractions of passively sensitized human bronchial smooth muscle (34). Finally, cromolyn sodium, tenidap and ketotifen block calcium conductance, which mediates refilling of the internal calcium ion pool of rat peritoneal mast cells (35). Theophylline inhibits phosphodiesterase activity, thereby elevating cytosolic levels of cAMP, and can therefore mediate a plethora of effects including modulation of cAMP-dependent chloride channels (eg, CFTR) and calcium homeostasis.

Similarly, the 14-membered macrolide antibiotics erythromycin and roxithromycin inhibit acetylcholine-activated chloride currents in guinea-pig nasal gland cells (36); the 16-membered josamycin has no such effect. Erythromycin, roxithromycin and clarithromycin also reduce neurally evoked cholinergic responses, but not those to exogenously added cholinergic agonist, in isolated human bronchus (37). The concentrations required to achieve these effects greatly exceed conventional therapeutic doses.

In light of the influence that these commonly used clinical agents may have on ion channels and calcium homeostasis, and the ramifications this has on ASM excitability, it is imperative to examine these issues in human ASM.

Novel agents designed to block a common signalling pathway: The cholinergic innervation and inflammatory mediators (particularly histamine and the leukotrienes) play key roles in the excitation of ASM. As such, past and present approaches to treating the immediate symptoms of asthma have included anticholinergics, antihistamines and leukotriene receptor antagonists $(17,27)$. However, it has been shown that spasmogens mediate their effects on ASM via a convergent signalling pathway: all release a common pool of calcium ions, which triggers the same changes in ion channel activity and contraction (Figure 8). In light of this, it may be more generally useful to use antagonists that act at one of the steps in this signalling pathway to interfere with the bronchoconstriction produced by any or all of the spasmogens.

For example, agents that can deplete the internal pool of calcium ions would completely eliminate the component of contraction that depends on release of internal calcium ions, as well as the component that is related to voltage-dependent calcium influx (since the depolarization is triggered by calcium release). Thapsigargin and cyclopiazonic acid are two chemically unrelated substances used experimentally to inhibit the calcium pump on the internal calcium ion pool of ASM (38); inhibition of the calcium pump leads ultimately to depletion of the calcium ion pool and loss of the electrophysiological responses to acetylcholine (38).
Similarly, it was found that decreasing the cytosolic concentration of chloride ion is associated with a decrease in the contractile response to acetylcholine in single ASM cells (1). Although the mechanism underlying this effect is unclear, this observation may suggest a potential use for agents that modulate chloride ion transport mechanisms and chloride channels in the antagonism of bronchoconstriction.

Finally, since excitation of ASM involves membrane depolarization (Figure 3), which in turn is mediated by the opening of chloride channels (Figures 5,6) and suppression of potassium channels (Figure 7), the use of chloride channel antagonists and/or potassium channel agonists may eventually prove useful in reversing bronchoconstriction. For this reason, it is interesting that niflumic acid is capable of both blocking chloride channels (Figure 7) $(1,2,4,6)$ and activating potassium channels (39).

\section{CONCLUSIONS}

A number of tools are available to characterize ion currents, including voltage clamp electrophysiology (to obtain the I-V relationship), ion substitution experiments, and pharmacological agonists and antagonists. We have used these techniques to characterize the membrane conductance changes underlying membrane depolarization in ASM, finding them to include a transient activation of chloride channels and prolonged suppression of potassium channels. Both conductance changes are triggered by release of internally sequestered calcium ions and, in turn, lead to opening of voltage-dependent calcium channels; the resultant influx of calcium ions contributes to contraction as well as to refilling of the internal calcium ion pool. Bronchodilators, on the other hand, act in part through activation of potassium channels, with consequent closure of calcium channels. The hallmark features of asthma include bronchoconstriction and hyperresponsiveness to spasmogens, both of which are secondary to inflammation of the airway, and may involve changes in ion channel activity in the ASM, including increased membrane conductance to sodium and calcium ions.

This relationship between ion channel activity and ASM function and dysfunction has important ramifications with respect to the treatment of asthma and related breathing disorders. For example, bronchoconstriction may be reversed by chloride channel antagonists or potassium channel agonists. One recently developed class of agents (cromakalim, levcromakalim) directly activates potassium channels; the type of channels affected are distinct from those regulated by beta-agonists. In addition, many antiallergic agents (furosemide, cromolyn, nedocromil, theophylline) commonly used in the treatment of asthmatics, as well as certain antibiotic agents (erythromycin), have been shown to block chloride channels and/or open potassium channels. Finally, antagonism of the common signalling pathway by which spasmogens act (ie, release of internally sequestered calcium ions) may be a useful way to prevent the effects of a wide range of spasmogens, in contrast to the current approach of selectively blocking one or another type of receptor. 


\section{REFERENCES}

1. Janssen LJ, Sims SM. ACh activates nonselective cation and chloride conductances in canine and guinea-pig tracheal myocytes. J Physiol 1992;453:197-218.

2. Janssen LJ, Sims SM. Histamine activates $\mathrm{Cl}^{-}$and $\mathrm{K}^{+}$currents in guinea-pig tracheal myocytes: convergence with muscarinic signalling pathway. J Physiol 1993;465:661-77.

3. Janssen LJ, Sims SM. Substance P activates $\mathrm{Cl}^{-}$and $\mathrm{K}^{+}$conductances in human bronchial smooth muscle. Can J Physiol Pharmacol 1994;72:705-10

4. Janssen LJ. Acetylcholine and caffeine activate $\mathrm{Cl}^{-}$and suppress $\mathrm{K}^{+}$ conductances in human bronchial smooth muscle. Am J Physiol 1996;270:L772-81.

5. Janssen LJ, Sims SM. Spontaneous transient inward currents and rhythmicity in canine and guinea-pig tracheal myocytes. Pflugers Arch 1994;427:473-80.

6. Janssen LJ, Sims SM. $\mathrm{Ca}^{2+}$-dependent $\mathrm{Cl}^{-}$current in canine tracheal smooth muscle cells. Am J Physiol 1995;269:C163-9.

7. Allen SL, Cortijo J, Foster RW, Morgan GP, Small RC, Weston AH. Mechanical and electrical aspects of the relaxant action of aminophylline in guinea-pig isolated trachealis. Br J Pharmacol 1986;88:473-83.

8. Allen SL, Beech DJ, Foster RW, Morgan GP, Small RC. Electrophysiological and other aspects of the relaxant action of isoprenaline in guinea-pig isolated trachealis. Br J Pharmacol 1985;86:843-54.

9. Jones TR, Charette L, Garcia ML, Kaczorowski GJ. Selective inhibition of relaxation of guinea-pig trachea by charybdotoxin, a potent $\mathrm{Ca}^{++}$-activated $\mathrm{K}^{+}$channel inhibitor. J Pharmacol Exp Ther 1990;255:697-706.

10. Jones TR, Charette L, Garcia ML, Kaczorowski GJ. Interaction of iberiotoxin with $\beta$-adrenoceptor agonists and sodium nitroprusside on guinea-pig trachea. J Appl Physiol 1993;74:1879-84.

11. Murray MA, Berry JL, Cook SJ, Foster RW, Green K, Small RC. Guinea-pig isolated trachealis: the effects of charybdotoxin on mechanical activity, membrane potential changes, and the activity of plasmalemmal K ${ }^{+}$-channels. Br J Pharmacol 1991;103:1814-8.

12. Miura M, Belvisi MG, Stretton CD, Yacoub MH, Barnes PJ. Role of potassium channels in brochodilator responses in human airways. Am Rev Respir Dis 1992;146:132-6.

13. Kume H, Takai A, Tokuno H, Tomita T. Regulation of $\mathrm{Ca}^{2+}$-dependent $\mathrm{K}^{+}$channel activity in tracheal myocytes by phosphorylation. Nature 1989;341:152-4.

14. Goldie RG, Spina D, Henry PJ, Lulich KM, Paterson JW. In vitro responsiveness of human asthmatic bronchus to carbachol, histamine, $\beta$-adrenoceptor agonists and theophylline. Br J Pharmacol 1986;22:669-76.

15. Honda K, Satake T, Takagi K, Tomita T. Effects of relaxants on electrical and mechanical activities in the guinea-pig isolated tracheal muscle. Br J Pharmacol 1986;87:665-71.

16. Murray MA, Boyle JP, Small RC. Cromakalim-induced relaxation of guinea-pig isolated trachealis: antagonism by glibenclamide and by phentolamine. Br J Pharmacol 1989;98:865-74.

17. Kaliner MA. Evolution of asthma treatments. Ann Allerg 1993;71:300-5.

18. Andersson K-E. Airway hyperreactivity, smooth muscle and calcium. Eur J Respir Dis 1983;64(Suppl 131):49-70.
19. Middleton E. Airway smooth muscle, asthma, and calcium ions. J Allerg Clin Immunol 1984;73:643-50.

20. Triggle DJ. Calcium, the control of smooth muscle function and bronchial hyperreactivity. Allergy 1983;38:1-9.

21. Souhrada M, Souhrada JF. Immunological changes of airways smooth muscle reactivity. In: Raeburn D, Giembycz MA, eds. Airways Smooth Muscle: Development and Regulation of Contractility. Basel: Birkhaüser-Verlag, 1994:219-58

22. Small RC, Foster RW. Electrophysiological behavior of normal and sensitized airway smooth muscle. Am Rev Respir Dis 1987;136:S7-11.

23. Black JL, Marthan R, Armour CL, Johnson PRA. Sensitization alters contractile responses and calcium influx in human airway smooth muscle. J Allerg Clin Immunol 1989;84:440-7.

24. Liu S, Schreur KD. G protein-mediated suppression of L-type $\mathrm{Ca}^{2+}$ current by interleukin- $1 \beta$ in cultured rat ventricular myocytes. Am J Physiol 1995;268:C339-49.

25. Black JL, Armour CL, Johnson PRA, Alouan LA, Barnes PJ. The action of a potassium channel activator, BRL 38277 (lemakalim), on human airway smooth muscle. Am Rev Respir Dis 1990;142:1384-9.

26. Weston $\mathrm{AH}$. Smooth muscle $\mathrm{K}^{+}$channel openers: their pharmacology and clinical potential. Pflugers Arch 1989;414:S99-105.

27. Barnes PJ. Anti-inflammatory therapy for asthma. Ann Rev Med 1993;44:229-42.

28. Chung KF. Furosemide and other diuretics in asthma. J Asthma 1994;31:85-92.

29. O'Donnell WJ, Israel E. Inhaled diuretics in asthma: the search for the mechanism of action. J Asthma 1994;31:79-83

30. Reinsprecht M, Pecht I, Schindler H, Romanin C. Potent block of $\mathrm{Cl}^{-}$ channels by antiallergic drugs. Biochem Biophys Res Commun 1992; 188:957-63.

31. Paulmichl M, Norris AA, Rainey DK. Role of chloride channel modulation in the mechanism of action of nedocromil sodium. Int Arch Allerg Immunol 1995;107:416.

32. Jackson DM, Pollard CE, Roberts SM. The effect of nedocromil sodium on the isolated rabbit vagus nerve. Eur J Pharmacol 1992;221:175-7.

33. Hurst AM, Hunter M. Apical membrane potassium channels in frog diluting segment: stimulation by furosemide. Am J Physiol 1992;262:F606-14

34. Pavord I, Holland E, Baldwin D, Tattersfield A, Knox A. Effect of diuretics on allergen-induced contractions of passively sensitized human bronchi in vitro. Am J Respir Crit Care Med 1995;152:1164-9.

35. Franzius D, Hoth M, Penner R. Non-specific effects of calcium entry antagonists in mast cells. Pflugers Arch 1994;428:433-8.

36. Ikeda $\mathrm{K}, \mathrm{Wu} \mathrm{D}$, Takasaka T. Inhibition of acetylcholine-evoked $\mathrm{Cl}^{-}$ currents by 14-membered macrolide antibiotics in isolated acinar cells of the guinea pig nasal gland. Am J Respir Cell Mol Biol 1995; $13: 449-54$

37. Tamaoki J, Tagaya E, Sakai A, Konno K. Effects of macrolide antibiotics on neurally mediated contraction of human isolated bronchus. J Allerg Clin Immunol 1994;95:853-9.

38. Janssen LJ, Sims SM. Emptying and refilling of $\mathrm{Ca}^{2+}$ store in tracheal myocytes as indicated by ACh-evoked currents and contraction. Am J Physiol 1993;265:C877-86.

39. Ottolia M, Toro L. Potentiation of large conductance $\mathrm{K}_{\mathrm{Ca}}$ channels by niflumic, flufenamic, and mefanamic acids. Biophys J 1994;67:2272-9. 


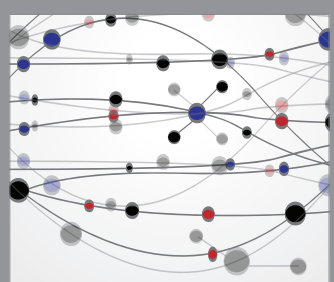

The Scientific World Journal
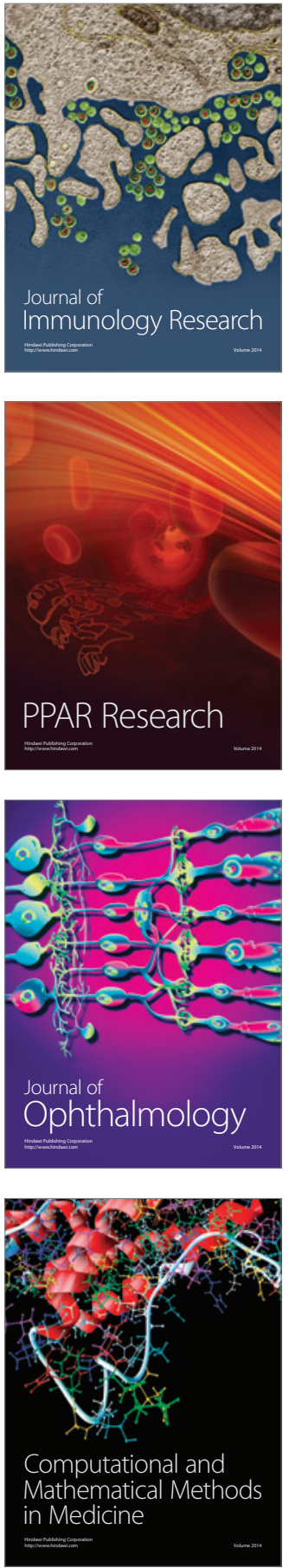

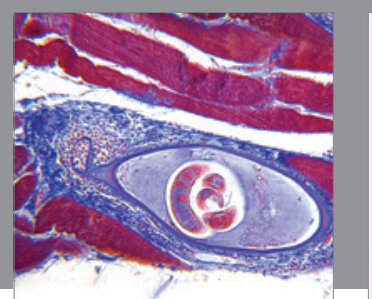

Gastroenterology Research and Practice

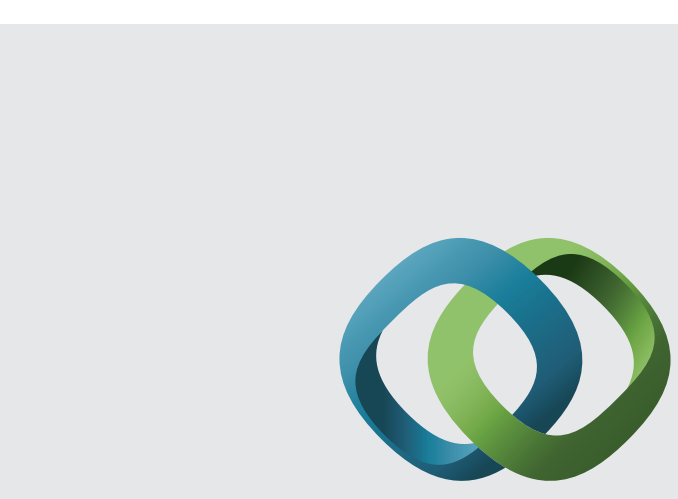

\section{Hindawi}

Submit your manuscripts at

http://www.hindawi.com
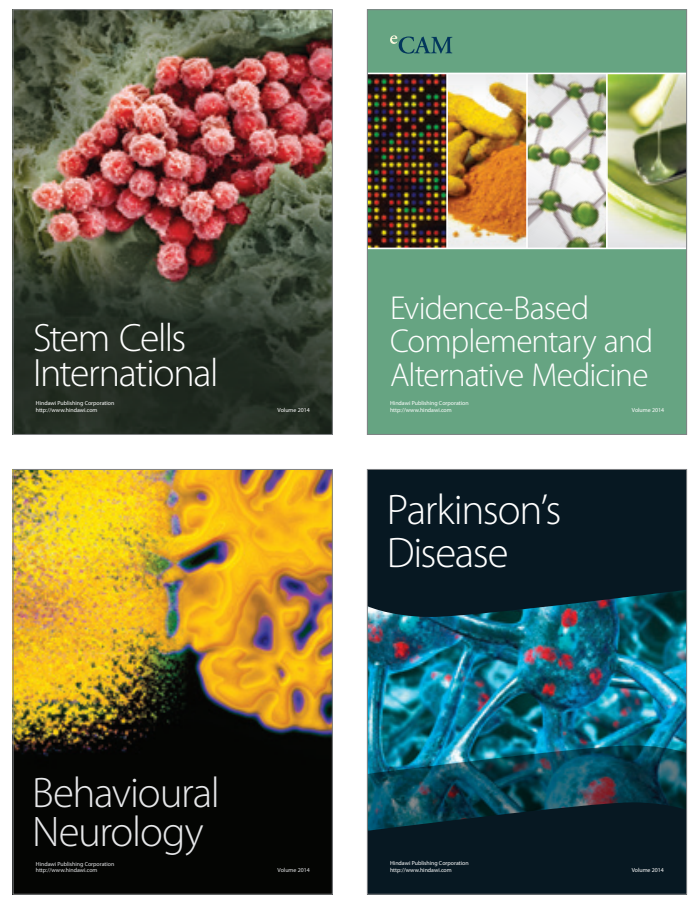
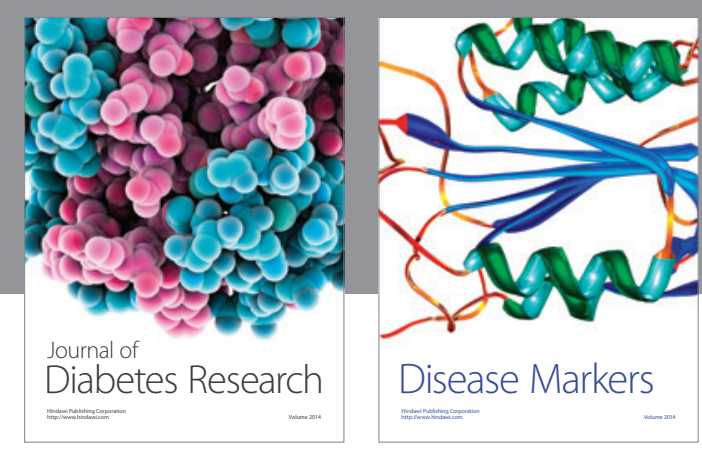

Disease Markers
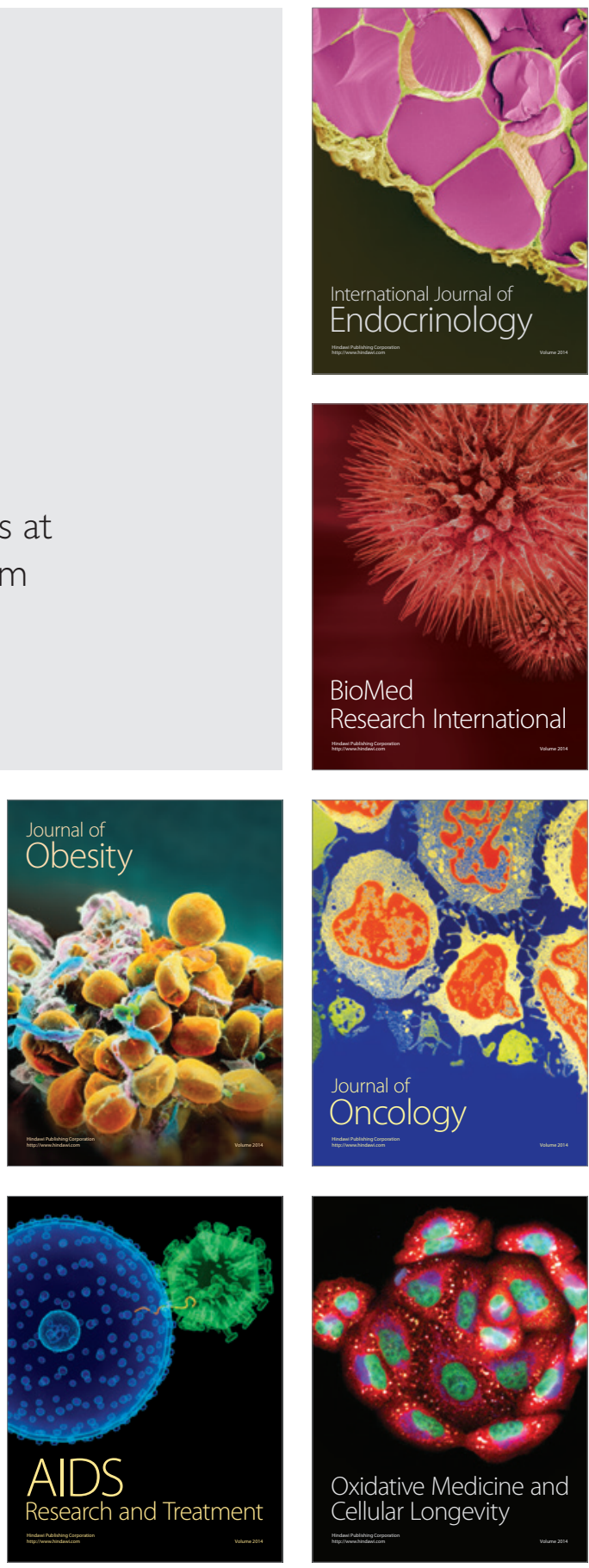